\title{
PENETRAÇÃO DE ÍONS CLORETO EM ESTRUTURAS DE CONCRETO ARMADO
}

\author{
W. MAZER ${ }^{1}$, G. MACIOSKI ${ }^{1}$ e N. SOTO ${ }^{2}$ \\ ${ }^{1}$ Universidade Tecnológica Federal do Paraná, Departamento de Construção Civil \\ ${ }^{2}$ Universidade Tecnológica Federal do Paraná, Departamento de Projetos e Obras \\ E-mail para contato: gmacioski@utfpr.edu.br
}

\begin{abstract}
RESUMO - A corrosão da armadura é uma das mais generalizadas patologias do concreto armado. Inicialmente esse processo manifesta-se através de manchas provenientes do Óxido de ferro e devido à característica expansiva dos produtos resultantes da corrosão, assim pode ocorrer fissuração, desagregação e desplacamento do concreto. O objetivo principal deste trabalho é analisar o ingresso de íons Cloretos no concreto através da moldagem de corpos-de-prova colocados em água com $5 \%$ de $\mathrm{NaCl}$. $\mathrm{O}$ teor de íons cloretos foi determinado através de Titulometria Potenciométrica. Quando um metal está imerso em uma solução que contém seus próprios íons, instala-se um potencial de eletrodo, cujo valor é dado pela equação de Nernst. Conforme proposto, determinou-se a concentração de íons Cloretos totais, na idade de 18 meses e nas profundidades de $1 \mathrm{~mm}$ a $5 \mathrm{~mm}$, à $15^{\circ} \mathrm{C}$. Com tais dados foi possível traçar o perfil de penetração dos íons Cloreto e o entendimento deste mecanismo permite prever a durabilidade da estrutura.
\end{abstract}

\section{INTRODUÇÃO}

A ação de agentes agressivos sobre o concreto armado provoca sua degradação que, segundo Johnson (1969) e Martin-Pérez et al. (2000), possui como principais sintomas as fissuras, a desagregação e as manchas. Os íons Cloretos, ao entrarem em contato com as armaduras em níveis superiores a uma quantidade chamada de concentração crítica, dão início a um processo corrosivo das armaduras, que, inicialmente, se manifesta através de manchas provenientes do Óxido de ferro. Em uma segunda etapa, devido à característica expansiva dos produtos da corrosão, pode ocorrer uma fissuração do concreto seguida de sua desagregação.

A corrosão das armaduras também produz uma redução da seção transversal da armadura, diminui a aderência entre o concreto e o aço e produz um aumento do volume do aço, gerando tensões internas, sendo que tais situações podem levar a um risco de colapso estrutural (CÁNOVAS, 1988, MARTIN-PÉREZ et al., 2000).

Tais íons podem penetrar em uma estrutura de diversas formas, entre elas cita-se (FIGUEIREDO, 2005): uso de aceleradores de pega que contenham Cloreto de Cálcio (CaCl2); impurezas nos materiais utilizados para a confecção do concreto; ação da atmosfera marinha (maresia); contato com a água do mar; alguns processos industriais; uso de sais de degelo, entre 
outros. Uma vez presentes na massa de concreto, os íons Cloretos podem estar combinados com os compostos do cimento, fisicamente adsorvidos na superfície dos poros capilares ou ainda livres nos poros do concreto. São os íons livres que podem chegar até as armaduras e dar início a um processo corrosivo como apresentado na Figura 1, diminuindo a vida útil da estrutura (FIGUEIREDO, 2005).

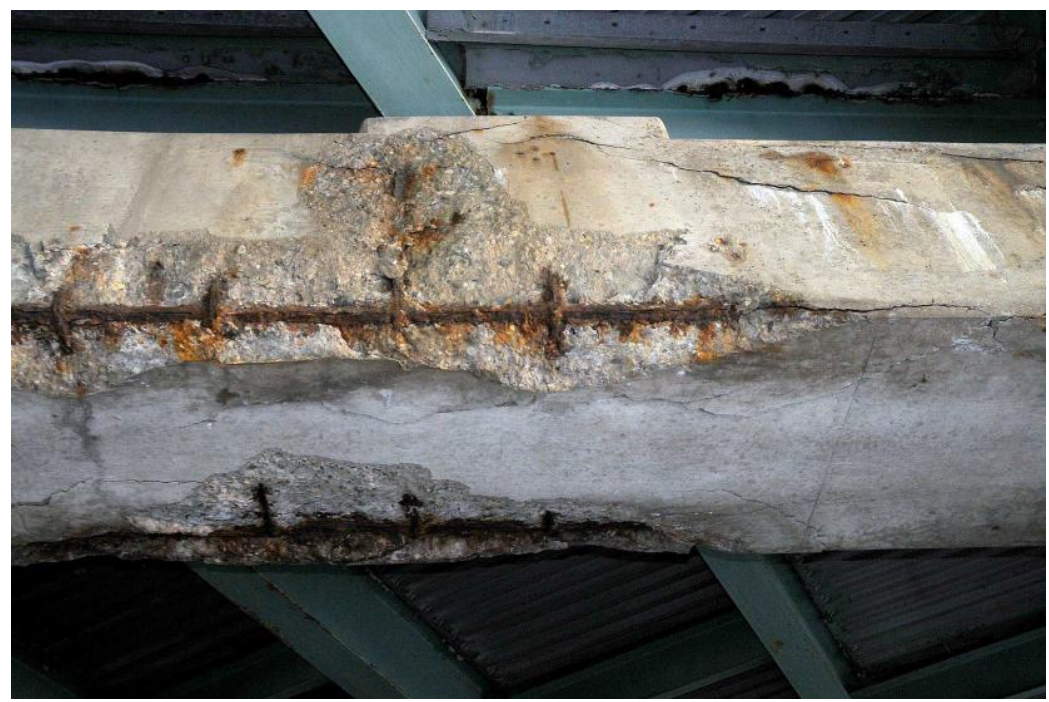

Figura 1 - Viga de concreto armado atacada por sulfatos

O objetivo principal deste trabalho é o analisar o ingresso de íons Cloretos no concreto armado em diferentes profundidades de uma peça exposta a íons cloretos com base em dados experimentais obtidos através de potenciometria titulométrica.

\section{AÇÃO DE ÍONS CLORETO NO CONCRETO ARMADO}

A corrosão das armaduras causada pela ação dos íons Cloretos é apresentada como uma das principais causas de degradação das estruturas de concreto armado (AL-KHAJA, 1997; JENSEN et al., 1999; ARYA e XU, 1995; entre outros). Esta corrosão é resultante de um processo eletroquímico, acompanhado de reações anódicas e catódicas. Segundo Mehta (1982) as reações que ocorrem devido a ação dos íons Cloretos são as apresentadas nas Equações 1 e 2.

- Reação anódica envolvendo íons $\mathrm{Cl}^{-}$

$$
\mathrm{Fe}+2 \mathrm{Cl}^{-} \rightarrow \mathrm{FeCl}_{2} \rightarrow \mathrm{Fe}^{++}+2 \mathrm{Cl}^{-}+2 \mathrm{e}^{-2}
$$

- Reação catódica 


$$
1 / 2 \mathrm{O}_{2}+\mathrm{H}_{2} \mathrm{O}+2 \mathrm{e}^{-} \rightarrow 2(\mathrm{OH})^{-}
$$

Para Gentil (2003), os íons de Ferro formados na região anódica migram para a região catódica, enquanto que os íons Hidroxilas formados na região catódica migram em direção ao ânodo. $\mathrm{O}$ encontro destes íons se dá em uma região intermediária, formando o Hidróxido ferroso, mostrado na equação 3, o qual sofre uma transformação dando origem a outros compostos. Estes novos compostos dependem da oxigenação do meio; como nas estruturas de concreto armado o meio encontra-se oxigenado, forma-se o Hidróxido de ferro expansivo como indicado na equação 4.

- Formação do Hidróxido de ferro II

$$
\mathrm{Fe}^{++}+2 \mathrm{OH}^{-} \rightarrow \mathrm{Fe}(\mathrm{OH})_{2}
$$

- Formação do Hidróxido de ferro III expansivo

$$
2 \mathrm{Fe}(\mathrm{OH})_{2}+\mathrm{H}_{2} \mathrm{O}+1 / 2 \mathrm{O}_{2} \rightarrow 2 \mathrm{Fe}(\mathrm{OH})_{3}
$$

$\mathrm{Na}$ Tabela 1 estão indicados os limites máximos de íons Cloretos permitidos pelas normas técnicas de alguns países.

Tabela 1 - Valores críticos de íons Cloretos em concreto armado

\begin{tabular}{|c|c|c|c|}
\hline PAÍS & NORMA & LIMITE DE CL & REFERÊNCIA \\
\hline EUA & ACI 318,2001 & $0,3 \%$ & Cimento \\
\hline EUROPA & EUROCODE 2,1991 & $0,4 \%$ & Cimento \\
\hline JAPÃO & JSCE-SP 2,1986 & $0,6 \mathrm{~kg} / \mathrm{m}^{3}$ & Concreto \\
\hline BRASIL & NBR 12655 & $0,4 \%$ & Cimento \\
\hline
\end{tabular}

Fonte: adaptado de DURAR, 1997

\section{MATERIAIS E MÉTODOS}

Para se determinar a concentração de íons cloreto em peças de concreto, foram moldadas peças prismáticas - Figura 2. Inicialmente, efetuou-se uma dosagem pelo método ABCP com cimento CP II - Z, obtendo-se o traço $1: 1,32: 1,97: 0,41$ (cimento : areia : brita : relação água/cimento). Após isso se efetuou um processo de cura de 28 dias em câmara úmida, e submeteram-se os corpos-de-prova ao ambiente agressivo em temperatura de $15^{\circ} \mathrm{C}$. Os tanques foram preparados com solução de $5 \%$ de $\mathrm{NaCl}$. 


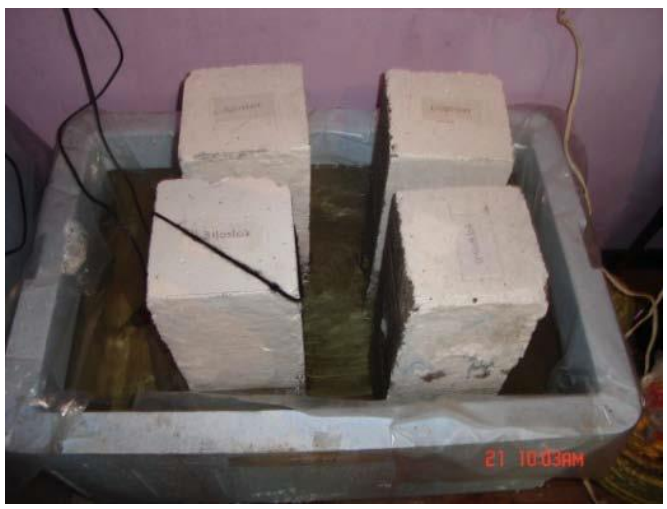

Figura 2 - Corpos-de-prova no tanque

Para a utilização do método, os corpos-de-prova foram perfurados nas profundidades de 1 a 5mm, após 18 meses submersos em tanque. For fim foram extraídas amostras do concreto através da perfuração das amostras até a profundidade de interesse. Com o pó retirado foi realizado o ensaio de titulometria potenciométrica. O ensaio e o aparelho utilizado podem ser observados nas figuras 3 e 4 .

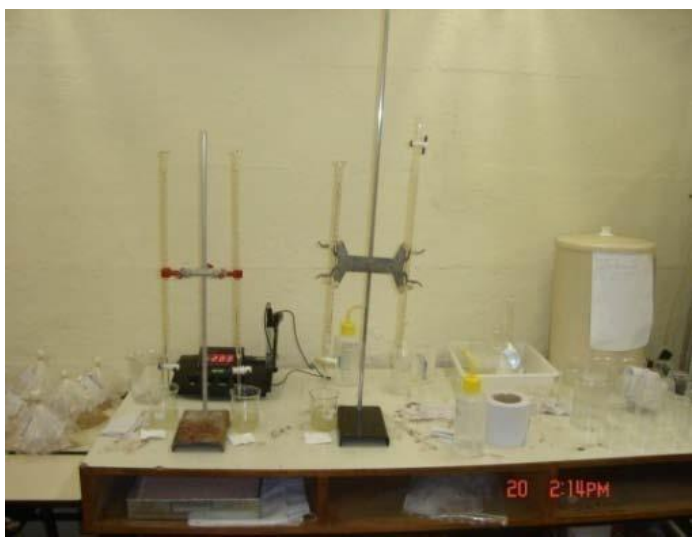

Figura 3 - Ensaio de titulação

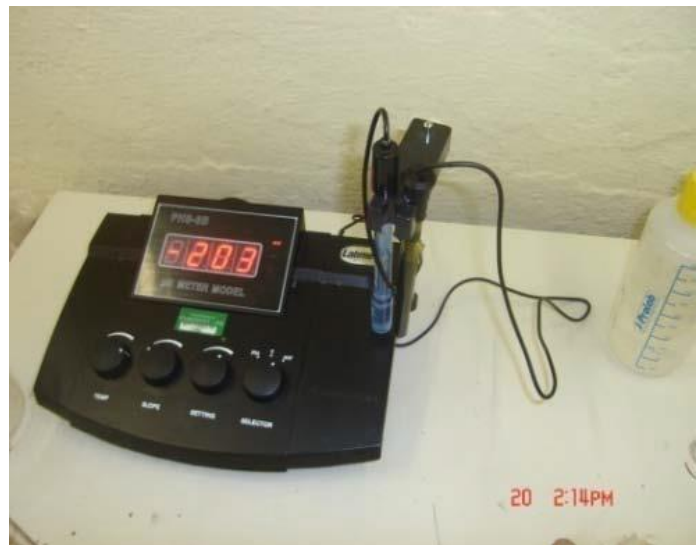

Figura 4 - Aparelho PHametro

Quando um metal está imerso em uma solução que contém seus próprios íons, instala-se um potencial de eletrodo, cujo valor é dado pela equação de Nernst - Equação 5.

$\mathrm{E}=\mathrm{E}^{\theta}+\left(\frac{\mathrm{RT}}{\mathrm{nF}}\right) \cdot \ln \left(\mathrm{a}_{\mathrm{M}_{\mathrm{n}}}\right)$

Onde: E representa o potencial elétrico; $\mathrm{E}^{\theta}$ é o potencial padrão do eletrodo do metal; $\mathrm{R}$ é a 
constante dos gases $(8,3144 \mathrm{~J} / \mathrm{Kmol})$; $\mathrm{T}$ é a temperatura em Kelvin; F é a constante de Faraday $(96.485,3 \mathrm{C} / \mathrm{mol}) ; \mathrm{n}$ representa o número de elétrons envolvidos e $\mathrm{a}_{\mathrm{M}_{\mathrm{n}}+}$ representa a concentração de íons do metal, em mol/L.

No caso de determinação da concentração de íons Cloreto no concreto, após o preparo da solução, efetuam-se leituras do potencial elétrico a cada adição do reagente de Nitrato de Prata. Ao atingir um volume de Nitrato de prata que reaja com todos os íons Cloretos existente na amostra, ocorre uma variação brusca na leitura do potencial elétrico, podendo-se, então, determinar a concentração de íons Cloretos na amostra.

\section{RESULTADOS}

A partir dos ensaios realizados foi possível observar que existe uma variação da concentração de íons Cloretos em função da profundidade. A Figura 5 ilustra o perfil de penetração de íons Cloretos dos corpos-de-prova submetidos à agressividade ambiental durante 18 meses.

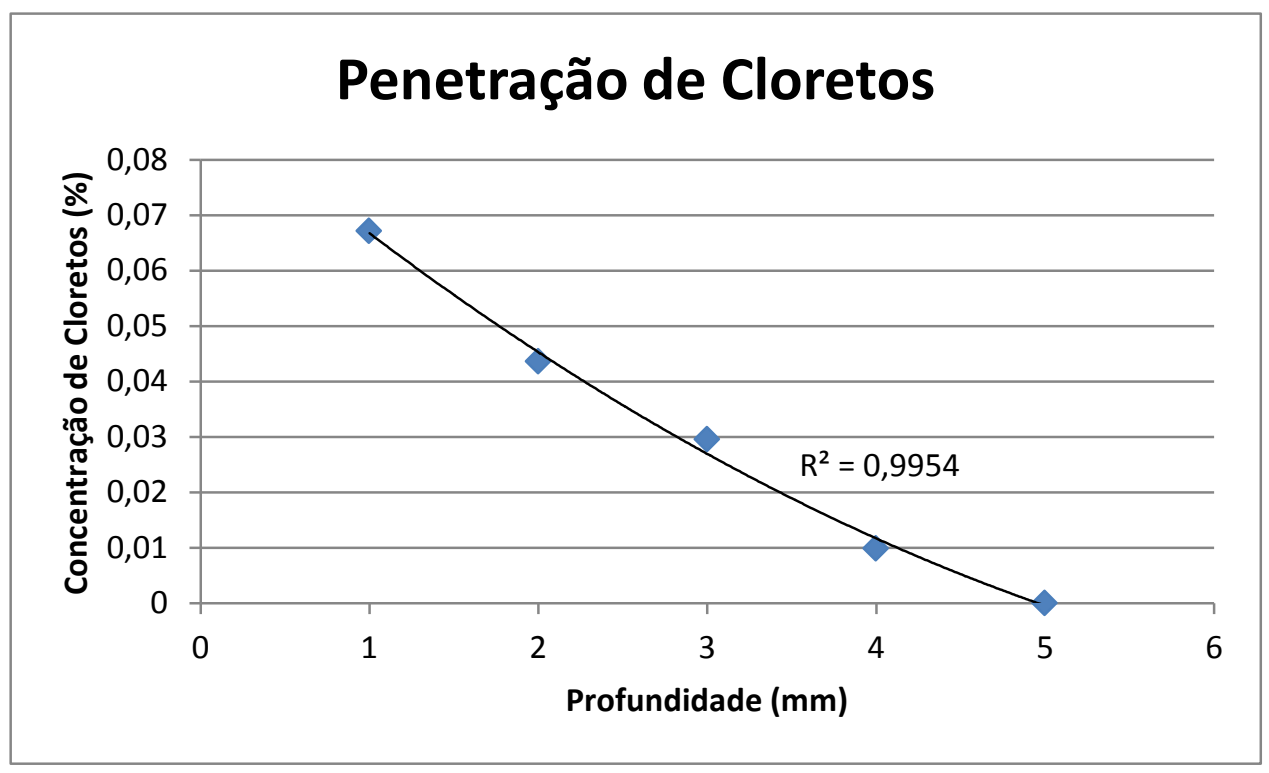

Figura 5 - Perfil de penetração de íons Cloretos

A partir dos resultados apresentados na Figura 5 pode-se afirmar que ocorreu uma redução dos teores de cloreto conforme se avançou em direção ao interior da peça. No experimento, após 18 meses, não foi atingido o limite máximo estabelecido pelas normas vigentes, ao contrario do esperado. Acredita-se que isto ocorreu porque foram utilizados corpos-de-prova de concreto feitos em laboratório adensados conforme prescrições normativas e submetidos à agressividade ambiental após 28 dias de cura submersa, sendo que, em estruturas reais, estas etapas são executadas de forma 
deficiente, facilitando a penetração de agentes agressivos. Além disso, em ambiente laboratorial os corpos de prova estavam protegidos de outras degradações e agressões, que são cumulativas nas estruturas.

O valor máximo de $0,0671 \%$ para concentração de cloretos foi encontrado na superfície da estrutura $(1 \mathrm{~mm})$, chegando a valores nulos na profundidade de $5 \mathrm{~mm}$. Como por norma o cobrimento mínimo (distancia entre a superfície da peça e a armadura) do concreto armado é de $25 \mathrm{~mm}$, nessas condições a armadura estaria protegida das reações expansivas que diminuem a vida útil das estruturas após corrosão.

\section{CONCLUSÃO}

A partir dos ensaios realizados e da analise dos resultados apresentados foi possível concluir que o método de titulométrica potenciométrica mostrou-se preciso para a determinação da concentração de íons cloreto no concreto e forneceu um perfil coerente de concentração, variando com a profundidade.

Além da variação observada na penetração de íons cloreto, nota-se também que a difusão destes íons não ocorre de forma linear, existindo portando necessidade de desenvolver modelo matemático que descreva o comportamento da penetração. De forma geral a difusão de matéria ou energia onde não existe equilíbrio químico obedece à Lei de Fick, que é apresentada na forma de uma equação diferencial no espaço e no tempo, exigindo, portanto, o controle de um número maior de parâmetros durante o ensaio.

Desta forma, destaca-se a importância desse tipo de estudo para um melhor entendimento do comportamento do concreto quando exposto a agentes agressivos, uma vez que essa exposição está diretamente ligada com a vida útil e durabilidade das estruturas, além de prever o tempo necessário para que ocorra um ataque completo na estrutura. $\mathrm{O}$ estudo do comportamento do concreto armado quando exposto a compostos como íons cloreto permite que as estruturas sejam mais bem dimensionadas, evitando-se assim patologias e gastos com recuperação de pecas degradadas.

\section{REFERÊNCIAS}

JOHNSON, S. M., Dégradation, entretien et reparation des ouvrages du genie civil, Eyrolles, 1 . edição, Paris, 1969.

MARTIN-PÉREZ, B., PANTAZOPOULOU, S.J., THOMAS, M.D.A., Numerical solution of mass transport equations in concrete structures. Computers and Structures, vol. 79, pp. 1251-1264, 2001.

CÁNOVAS, M. F., Patologia e Terapia d Concreto Armado, Ed. Pini, 1ª Edição, São Paulo, 1988 
FIGUEIREDO, E.P., Concreto - Ensino, Pesquisa e Realizações, in ISAIA, G. C., São Paulo, IBRACON, 2005

AL-KHAJA, W. A., Influence of temperature, cement type and level of concrete consolidation on chloride ingress in conventional and high-strength concrete. Construction and Building Materials, vol. 11, no. 1, pp. 9-13, 1997.

JENSEN, O. M., HANSEN, P. F., COATS, A. M., GLASSER, F. P., Chloride ingress in cement paste and mortar. Cement ad Concrete Research, vol. 29, pp. 1497-1504, 1999

ARYA, C., XU, Y., Effect of cement type on chloride binding and corrosion of steel in concrete. Cement and Concrete Research, vol. 25, no. 4, pp.893-902, 1995.

MEHTA, K., Durability of concrete in marine environment - A review. In Performance of Concrete in Marine Environment, ACI, pp. 1-20, 1982

GENTIL, V., Corrosão, Ed. LTC, $4^{\mathrm{a}}$ edição, Rio de Janeiro, 2003.

DURAR: Manual de inspeccion, evaluacion y diagnostic de corrosion en estructuras de hormigon armado. CYTED, Rio de Janeiro, 1997 